\title{
Theatre as Tool for Development in Nigeria
}

\author{
Chukwukelue Uzodinma Umenyilorah
}

\begin{abstract}
Among the many communication tools available, theatrical representation is a favorite in many subSaharan African countries. Because of its festive, communal, realistic and concrete nature, it is almost impossible to avoid if you have a message to transmit to local communities - whether rural or urban.

When we talk about theatre in the development context, we are obviously not talking about classical theatre, but rather about popular forms of theatre also known as street theatre, intervention theatre, or theatre for development. The most popular forms of theatre for development are forum theatre, interactive theatre, and the theatre debate - all of which use similar techniques.

One of the distinguishing characteristics of popular theatre is its social content. The troupes of actors are often local or regional. The villagers do not have to travel to see the performances, as the troupes come to the villages to perform.

Within development, there is an increasing recognition of the need to hear the opinion of the people who are most affected by development. One response to this is 'Theatre for Development', which is a technique of performance and drama-building. It rests on an interaction between people who are in the flight path of development projects and those agencies who initiate them.

This paper will examine theatre as a powerful tool of communication which enables people to contribute in the development of their society and thereby get involved in the search for solutions.
\end{abstract}

Keywords: Africa, Communication, Development, Theatre, Enlightenment, Nigeria

\section{Introduction}

The theater is known to be alive to the social-political realities of its time; a kind of court where the economic, social, religious, and political issues of society are outlined, evaluated and judged. To bring about a better society, the theater, its practitioners, and in fact, all artists are vanguards of social change in their respective capacities- keeping a watchful eye and an attentive ear on the happenings in the society. Theater as an art form is a re-enactment of an event, which could either be real or imagined, and communicated to an audience through the medium in which the artist seeks to contact his audience. These media could be an integrated manipulation of various forms of art such as music, dance, songs, mime, poetry, painting, sculpture, architecture and so forth. Hence, it is an audio-visual impression on its audience. This effect is as a result of the arousal of the awareness of real or imagined situation of life being presented on stage by actors. Hence, the dramatist uses theatre to create awareness in the mind of the audience to change the ills of his society.

Theatre engages the attention of people through a dramatic presentation of problems. It makes the audience see their problems in fresh and critical ways. In addition, this is a very important potential of the theatre as an art form. When properly used by the artist, it could have a tremendous positive influence on the audience. In Africa, drama/theatre has always addressed the problems affecting the society ranging from cultural conflicts, to development problems, which include corruption, exploitation, and oppression. This is referred to as "Prams of Social Utility" that is using drama to address social anomalies.

The need to remain relevant as a dramatist has incited the African dramatist to evolve a dramatic form that is distinct. His aim in doing this is first to create an awareness by raising the consciousness of the masses to the situation that is oppressive and spur them into action that will liberate them. Secondly, it makes the masses see how they are being ruled or governed to understand the social situation that conditions them. It also aims at awakening the consciousness of the rural folks to understand the societal configuration that governs their lives, making them to have faith in themselves to undertake the struggle for change.

Nigerian theatre has played a serious role in the liberation and emancipation of the society from the clutches of primitive and debasing cultural practices. The majority of the people are rendered voiceless, socially degraded, psychologically dehumanized and economically disadvantaged by the oppressive leaders. In this oppressed society when an individual or group of individuals enact artistic performance, the oppressed masses are mobilized, having been conscientized, to stand up and fight against oppressive traditions like killing of twins, human trafficking, suicide bombing, kidnapping. 


\section{Drama as a cultural form}

Drama is more than just a mechanistic reflection of social reality. As part of man's artistic activities, it is in itself part of man's weapon for achieving change and self-realization as he struggles to overcome the forces inimical to his survival. It is a symbol of man's historical process of being and becoming. It is also an enjoyable end product of mans' artistic labor. However, importantly, it does shape our attitude to life and daily struggle to overcome the forces of nature.

Theater can be used for total transformation of the society. Through theatrical performance, the masses are able to determine what they consider to be the uses, abuses and misuses of power in their own environment. Through the ages, drama has proved its potential to arouse the consciousness of a people towards its social, political, and economic states. Many people think drama is a matter of laughter and uproar whereas it is a medium admirably suited for making deep psychological probes into the consciousness of a community. In African drama, theater has been instrumental to the liberation struggle and in the post-colonial days, it faced the problem of synthesizing the various ethnic groups that form a nation. However, most Africans have used the theater to revolt and fight against oppressive culture. The struggle for transformation of the foreign culture to that of Kenya was partly achieved through the means of the theater and music. In South Africa, theater and songs were used as agents of change in the society. Through them, people were made to see the oppression that they were passing through and to say "No" to the oppressive government of racial discrimination in their country.

Theater, in particular, could be used as a force for progressive change and transformation of our society. One thing is that drama, being presented on a stage, more easily equips the masses to shout out on the face of dehumanization. This is done through conscientization, leading the people to self-realization and selfdefinition. Drama, therefore, over the ages have fought unrelentlessly in presenting the right and better way to live with a view to betterment the lots of human existence. Drama through the process of social change or conscientization involves mystification. It is a process whereby men are made to see their problems as a consequence of a particular social order. It seeks to instill in the minds of the rural masses a great need for change. In Nigeria, as in most other African countries, theater imitates for the purpose of causing not only change in the moods of the people through entertainment, but also a change in their mindsets for the betterment of the socio-political and economic structure of the nation. In a more radical sense, theater practitioners do not only advocate for change but also spur the people to do so. This is exemplified in the popular theater process in which the practitioner only acts as a facilitator while the people do the actual advocating.

Theater has been found to be in constant dynamism with the political trends of the society in which it operates. Theater does not operate in a vacuum; it simply holds a mirror up to the society. Hence, the relevance of the theatre in this milieu is measured by how accurately it mirrors the realities of it's immediate society and points the way toward a higher ideals and more humane society. Theater has been known to initiate change. The impact of theater is direct and more immediate than any other form of artistic expression. The society cannot but heed the burning issues of social concerns as raised in contemporary plays. Nigeria is as ethnically heterogeneous as it is religiously fanatic. The Nigerian situation is such that our individual religious beliefs have come to be part of our culture and our everyday existence. Hence, the different religious groups in the country have long lost the original substance (faith) sustaining their individual beliefs. The idea that one can make different people into one nation by suppressing the ethnic or regional affiliations, which the people themselves are attached to, and highest political significance is simply non-plausible. The theater is therefore a potential check against tyranny, social ills and under development. This it does in a manner that promotes objective appreciation of genuine national political interests especially in a plural, multi ethnic and multi cultural nation such as Nigeria.

Theater is an apt forum through which ideas can be exchanged and social awareness disseminated. It can stimulate national discourse on crucial political issues, which may not find expedient expression through the conventional political fora. Because it is a social art that thrives on collaboration, interest harmonization and collective participation between the playwright, actor and the spectator, drama itself is a projector of democratic change. With a considerable improved rate of literacy and enhanced interest in the theater, democratic values and ideas expressed through drama will be made available to a broader spectrum of the populace. The consequent awareness will definitely contribute to the emergence and development of a genuinely democratic Nigeria.

\section{Theatre, A Tool For Development}

Development in Africa generally is characterized by conflict; oppositional pulls of polar and very often blurred, if not narrow perceptions. And these oppositions are still sharper when we talk about rural development. One of the fundamental aspects of rural development is problem identification. The success or failure of any project hinges on proper identification and the choice of the most biting problem for attention. This issue also raises the question of who identifies the problems and who finally decides what development a particular 
community needs. Theater has always been manipulated through the ages. A look at African theater especially the Nigerian traditional theater, literary theater, and radical literary theater, shows each, as being very effective in taking a particular position that tally with the held views and practices of the practitioners. It is not a question of right or wrong type of theater but essentially the use of theater through the generations has been an answer to the question.

Theatre for Development is therefore transformational, because when it involves the audience it is never a process that leaves off after the raising of a critical consciousness; rather it is one that leads to subsequent action.

In its 'popular' form, theater is able to reach the unreachable - the dwellers of the rural areas. The popular theater is the theater of consciousness that awakens the rural folks to understand their societal configurations as well as build faith in them as vectors of change. The awareness campaign championed by the theatre can lead the Nigerian masses into asking themselves questions such as why the Boko Haram is faceless, and can only be heard of on radios, read from pages of our dailies, making headlines on network news?, why the nation's schools and colleges are substandard for the children of those who belong to the political class?, why Nigerian graduates are not employable outside the country, not securing jobs in the country even when the Federal Government announced the provision of jobs for over one million youths?, why Nigerian banks are not being utilized by our politicians?, why Nigerian prisons is meant for the poor and innocent masses and the EFCC, ICP are toothless bull dogs?, why the queue in our filling stations will never end?, and why the global economic melt-down is only "melting up" with regard to our politicians?. These and many more issues are addressed by Theater for Development. The theater is sometimes as diplomatic as it can be rebellious in addressing issues of national concern. A look at a play such as Irobi's Nwokedi reveals the rebellious nature of the theater in the struggle against unacceptable standards. Here Irobi, (1987), Nwokedi, p.28. Recommends outright rebellion as the only remedy there is to tyranny and exploitative ruler ship. Hence, he writes:

'This is our moment, when we must gather our strength and energies into the demands of a revolution...this is the moment of revolt, of rebellion. We must revolt against those disembodied godheads (politicians) those spotted scavengers of Sahel Savannah'.

Applied theater is aimed at treating societal issues with the aim of improving standards. It was used effectively in Brazil in the constitutional reforms and passage of bills in the legislature. With its positive and participatory method, the masses were encouraged to take up suggestive correctional roles in drama which when considered as appropriate by the majority of audience are utilized in the making of government policies. Theater has served as an agent of socialization and education while entertaining the audience and a relevant tool in enhancing the development and improvement in the standard of living by the rural communities. Despite the attainment of political independence in 1960, Nigeria is practically stagnant. This has led to her being described variously as a developing nation, third world, African sleeping giant. It is indeed a beggar sleeping on a throne of gold. Reasons for the nations backwardness and little or no human development are multifarious and complex, but the often patronized is the over thirty - years of her military rule. From the 'operation feed the Nation' (OFN) of the late 70s, to the Austerity Measures' of the early 1980s, Structural Adjustment Program (SAP) of the 1990s, National Agency for Poverty Eradication Programme (NAPEP) of early 2000s to the third wave of democratic rule beginning in 1999, the nation can only boast of poverty, oppression, repression, unemployment, socio-political and religious conflicts, wars, and more recently, the suicide bombing in the Northern region; kidnapping in the Niger- Delta \& Eastern region; as major indices of development in her 51 years of independence. The much talked about democratic dividends is a sad commentary and a total paradox to the reality on ground.

Theatre for Development (TfD), understood as a problem solving, performance-oriented form of art is a process used in educating and conscientizing both the young old and unifying and articulating the community on socio-economic, political, environmental and religions problems. To achieve this objective, TFD works on the emotions, feelings, aspirations and sensibilities to arouse and galvanize the public who unfortunately are in the majority towards taking decisive actions on the directions of development within the polity. Babarinsa, (2003) in House of war p.18. Posits:

'Nigerian inability to manage her wealth is not the cause of her problem, but the consequences of her inability to manager her political fortune. Unlike the Noah's ark. The Nigerian leadership is laden with corrupt, greedy and megalomaniac captains while the passengers consider themselves as being fated in the hands of God'.

Development on the other hand is multi-dimensional phenomenon. Various societies have attained various levels of development and so, the approaches must differ from one society to another based on concrete realities of the peasant population who are always realities of the peasant population who are always in the majority. Nwamuo, (1990), in The Practice of Community Theatre in Nigeria, p75. Considers development from the rural point of view when he posits that: 
'Rural development is a process designed to create condition of economic and social progress for the whole community with its active participation and fullest possible reliance upon the community's initiative. It is stimulation of communities to change their own affairs constructively'.

Contrary to the above is the western bourgeoisie and government concept of development, which sees development in the context of per capital income. Development, from this perspective, is defined in terms of provision of infrastructures such as hospitals, electricity, pipe-borne water, airports and express roads. Again Nwamuo C. and Rodney W. analysis on development meets our requirement vis-à-vis the bed rock of theatre for Development. This is because development at any level must start with the individual, who in turn translates development into concrete visible areas for the society. Put in another form, human development is the bedrock of all other spheres of development economic, political, social and environmental development. The bourgeoisie and indeed the Nigerian government concept of development as seen above neither reflects nor improves the lives of the masses. This warped concept of development is responsible for the widening of the intellectual participation and, the raising of consciousness through the encouragements of dialogue.

Why have all the developmental programmers introduced by the Nigerian government remained counterproductive and outright failures? What really is responsible for the fact that despite the abundance oil, mineral and agricultural resources in the nation, Nigeria and her citizenry are still underdeveloped, unemployed and lacking? Onuoha, (2006), in The Nation, p.7. states 'Nigeria's low level of scientific and technological development is responsible for its poverty'. Should Nigeria continue to be ravaged by poverty despite her abundant resources? Nigeria is ranked among the sixteen (16) poorest nations of the world inspire of her abundant human and natural resources. This is indeed sad but true. The reasons for these are not far-fetched, Nigerian government with its top-bottom policy formulation has refused to learn from mistakes of the past. This is because, very often, the identification and final developmental project to be constructed becomes the exclusive prerogative of bureaucrats and technocrat in the urban centers who are alienated from the masses. The bureaucrats, following official laid-down criteria are removed from the realities of rural poverty. Thus, consultation and importantly too, participation in decision making by rural dwellers are consequently lost. Abah, (2005), in The Practice of Theatre for Development, p.15. Observed this lacuna when he posits:

'The success or failure of any one project hinges on proper identification and the choice of the most biting problem for attention. The issue of 'properness' also raises the question of who identifies the problems and finally decides what development a particular community needs. It is in this light that theatre for Development becomes relevant'.

Facilitators and resource personnel go into the various communities to interact with community heads, leaders and ward heads, otherwise known as gatekeepers. They seek permission to conduct interviews with the community members on their felt needs since 'it is he who wears the shoe can tell where it pinches' this enhances dialogue and participation, which are instrumental to any meaningful developmental program. This gesture promotes fairness, openness and above all, participation on the part of the community. This is even more so in Nigeria where conflicts, religious, ethnic and communal intolerance in the past, have stunted her developmental growth. Theatre for Development as a problem - solving process through is use of traditional machinery such as folk songs folklore, and drumming, dancing, storytelling and most importantly, its participatory and communicative prowess can be used to harness the various resources that had hither to been neglected. Apart, from this, its mode of operation is in total contrast to the Top-bottom government attitude of policy imposition and implementation as result of the gulf between the palace, mansions, pent house and the ghettoes, shacks and slums of the masses. The obvious anomaly becomes transparent in the implementation of the Bottom-Top policy since it operates on a participatory level. Nasiru, (1990), in Nigeria Society of Nigerian Artists, p.49. Observation is worth mentioning here:

When we think of theatre as a relevant tool in the task of community development, we must understand that we are asking from theatre and theatre personnel to place themselves at the disposal of government and for achieving objectives and goals that have been defined as matters of policy.

More positive is Etherton, (1982), in The Development of African Drama, p.320. Observations when Theatre for Development plays the role of media and the channel of information dissemination because:

'Drama in the context of these development programmes is like any other communication medium. It is objectively natural. Drama will reinforce the ultimate aims of the development programmes in which it is being used. Theaters will not, ipsofacto, transform the development programme either into what its superficial rhetoric declares it to be on into something else'.

This kind of theatre speaks to the people in their own language and idioms that deal with issues of direct relevance to their own lives. Development is achieved by, with, and for the community through dialogue once the awareness is created and the community in question is involved, their fate lies in their hands. Theatre for Development performs a dual role, the awareness which makes them see themselves as they are and as they ought to be there by taking the bull by the horn. The theatre is the state, the place, the point where we can get hold of man's anatomy and through it, heal and dominate his life. 


\section{Conclusion}

Theatre for Development is an instrument for raising consciousness. On another level, the lack of awareness on the part of the grass roots can impede development. The aim of raising consciousness is to change perspective in a critical and positive direction. TFD has become a way of galvanizing community groups and through which community art forms are validated. Theatre in the context of development is an on-going process. It is not an end in itself but a means to the development objective. In the debate regarding the mandate of TfD among amateurs two positions have emerged, one group sees the function as empowerment and the action on stage, which follows any workshop, should be the business of the people. For this group, the point of empowerment is the pull out stage. They just assess the needs of the target audience and deliver the solution in form of a message. The other position is that development amateurs should continue to play a linkage role even at the point that the grassroots organizations begin to take action. The linkage should be between the groups and development amateurs as well as between governments. These local groups are encouraged to define their own problems and to reach conclusions and solutions cooperatively. The relevance of this linkage factor should be seen against the background that the rural majority may be in experienced in dealing with government bureaucracies. Their performances form a basis for discussion and for cooperation between the community and experts. Issues are dealt with through dramatized case-studies. In this on-going practice the role of theatre is therefore not terminal. It is used at this stage to celebrate successes and to boost morale. Practitioners in this age are expected to talk, discuss and expose the issues that affect their society at a given time. They should be more of observers of their society. They should like Shakespeare be active critics and contributors to their communities by dealing with issues that are relevant that affect a wider populace of their communities at a given time. Shakespeare became relevant and reverenced in his days even till now because of his active involvement in dealing with intrinsic issues that affect mankind. TfD practitioners in the same way should copy this quality in Shakespeare and affect their society positively through their art.

Today, one of the greatest challenges of this form of theatre is its mode of communication to a wider audience in the same locality. We talk about the means of communication such as the internet, radio, television, films, and so forth through which people can get wind of these messages passed in whatever mode in which it has been packaged. A great part of the nation with emphasis on the southern part of the nation may have more access to cable network than their counterpart in the north. Due to the availability of cable networks like Dstv and so on, TfD could explore this medium in reaching out to the teeming populace of the south. Inspiring messages passed on via the cable networks could have some psychological effects (positively) on its audience. With reference to the adage 'when you get to Rome behave like Romans', this paper advocates for effective execution and implementation of developmental goals in the host communities, practitioners should go for communicative means that the community is quite conversant with. If in a community that the fastest and easiest means to reach them is the radio let the radio, be used as the means through which they can be reached. That invariably suggests that radio drama would be the best option for such a community. Practitioners should employ means that would be welcomed and appreciated by the host communities, anything that can make them embrace this form of theatre as tool for awareness, development and change we should employ that in achieving our goals. With the advent of social networking, information spread at a greater speed in the shortest possible time. This has helped development in almost every sphere of life at this age. TfD is not left out on this, practitioners have in so many ways have been using various channels in social networking like the Yahoo Messenger, Blackberry Messenger, 2go, Facebook, Twitter, You Tube and so on, to reach out to a wider audience. Audios and Videos are shot, recorded and uploaded on these channels/mediums for the audience to download. Social networks have been one of the positive steps towards greater heights practitioners have gained and explored in achieving developmental goals. In addition, by attacking the problems of one community, one might be solving the problem of another; the apparent stereotyping of indigenous African theatrical arts ambiguity is possible.

It is a known fact that this generation talks about the internet and there have been so many micro means through which the internet can be assessed- through their laptops, phones, tablets and so forth. In Africa, phones are the commonest means through which people assess that internet. If some of these performances are recorded in the forms of film, television, or radio dramas and posted on the internet for downloads and viewing, it will go a long way in reaching out to a wider audience of a particular community and beyond. Film serves as an interventionist tool in bridging the communication gap that has existed over the years. This advocacy for film in TfD has gone a long way in solving the problem of getting a government official to come and view some these performances by the communities. The advent of film to TfD has brought so much relief to the practitioners and the host communities. The awareness of using film to interact with people on developmental issues has been raised. In this wake of information technology, people prefer to watch movies online via their phones, laptops or tablets and this presents a faster, easier and safest means to reach out to a wider audience. In this regard, some practitioners no longer attack TfD from the standpoint of staging performances with the host communities rather such issues under study are discussed, treated and relayed through film by the community for the community 
and passed on to the appropriate agency/government in order to achieve results and the needs of the community met. Video CDs or DVDs of these performances are taken to the government or agencies for their perusal and adequate action.

In Nigeria, today, the level of insecurity has risen to a level where the government finds it too hard to combat the menace. This has become a great challenge for TfD and its practitioners in Nigeria. Film has become and remained the escaptionist means through which TfD practitioners attack developmental goals in the host communities especially in the Northern part of the country. TFD serves its purpose of being the bridge between the government and the rural communities. Through film, a community can educate and empower its members on new means of communication, Transportation, health care, security consciousness, and so forth. It must not necessarily involved practitioners coming to assist the community rather the community on its own employing this medium in reaching out to its members. I see it from the angle of 'performance of the community by the community and for the community, an intra-community education, empowerment and development.

It is believed that all these areas of work are dialectic in operation. Although designed for the benefit of the individual and the community, such theatre operates within government policy and does not seek to challenge the social and political status quo. It can be seen as open to political manipulation, either by government agencies operating through the influential sections of the community who are more articulate and better organized and who speak with traditional like authority like a traditional ruler, chief or someone in the Executive council of the community. Utilization of theatre often leads to an understanding on the part of those being educated that issues are being subverted or that questions are being begged. Once started the question of self education is difficult to prevent awkward question arising. There have been cases of literacy groups out growing their functions and wielding their work to share the new awareness with their fellow members of the community.

TfD practitioners in this regard must play extensive supervisory role in ensuring the dream of the programme is not defeated at any point. Proper guidance and advice should be ensured though education and empowerment in order to prevent the misuse of this initiative and opportunities. To deal with this, practitioners need to hammer the point home throughout the workshop period that they are not providers of solutions but that they are people engaging in discussing options and strategies, which the community may explore in dealing with their problems. To be effective however, some of the groups have to target and convince the opinion leaders and base group leaders and members of the community who command respect and constitute the action nucleus within the community. This is why the successes of the workshops should in part be measured by how much it strengthens existing base groups. TfD is essentially a theatre of participation and liberation. A participatory theatre approach in discussing community development issues towards participatory and communal approaches as well as acceptance and validation of the already existing communal system.

Given the politico-cultural heterogeneity of Nigeria, introduction of new laws and practices and their attendant implementation challenges like in the Health sphere, could best be done with lesser stress via indigenous theatrical performances targeted at highlighting, analyzing with the view of offering solutions, all obsolete local view thereby increasing the giant strides of improving the concept of "EDUTAINMENT" as is already the trend in most African countries.

\section{References}

[1]. Abah, O.S., 1990. 'Participatory Theatre: Issues and Cases in Community Theatre in Nigeria', In: The Practice of Community Theatre in Nigeria (ed.) Iyorwuese Hagher. Society of Nigerian Artists,

[2]. Abah, O.S.,2005. 'Performing Live: Case Studies', In: The Practice of Theatre for Development. Lagos: Baraka Press and Publishers Limited.

[3]. Achebe, C., 1981. 'The African Writers and the Biafran Cause' In: Morning Yet on Creation Day. London: Heinemann Press.

[4]. Nasiru. A.,1990. 'The Nigerian Theatre and Community Development Myth, Reality or Wishful Thinking', In: Nigeria Society of Nigerian Artists (SONTA). Pp $47-53$

[5]. Alachi, J.A.,2008. Theatre for Development in the Benue Valley" (ed.). Makurdi: Bookmakers Publishers.

[6]. Arendshorst, T.K.,2005. 'Drama and Conflict Transformation: Beyond Intractability' (ed.). Guy Bugress and Heid Bugress. Conflict Research Consortium. University of Colorado, Boulder. \{http://www.beyondintractability.org/essay/drama/\} assessed June, 2012 .

[7]. Babarinsa, Dare.,2003. House of War. Ibadan: Spectrum Books Limited and Tell Communication. Lagos.

[8]. Brain, W., 1985. Development Through Drama. Singapore: Selector Printing.

[9]. Nwamuo, C.,1990. 'Rural Development in Nigeria: The Community Theatre Paradigm' In: The Practice of Community Theatre in Nigeria (ed.) Iyorwuese Hagher. Society of Nigerian Artists (SONTA). Pp $74-93$.

[10]. Etherton, M.,1982. The Development of African Drama”. London: Hat Chington for Africa.

[11]. Onuoha. G.,2006. 'Why Nigerians are Poor' In: The Nation. A Nigerian Daily Newspaper, Pp 7.

[12]. Hagher, H. Iyorwuese., 1990. "The Practice of Community Theatre in Nigeria". Lagos: Lobi Consortium Limited Publishers.

[13]. Irobi, Esiaba.,1989. Hangmen Also Die. Enugu: ABIC Publishers.

[14]. Irobi, Esiaba.,1999. Nwokedi. Enugu: ABIC Publishers.

[15]. Kerr, David.,1995. African Popular Theatre. London: Villiers Publications Limited.

[16]. Ngugi, W.O., 1981. Writers in Politics. London: Heinemann Educational book.

[17]. Obadiegwu, C.C., 2004 'Beyond the Fourth Wall' In: Theatre at the Frontier of Human Development. Awka: Penmark Publishers. 
[18]. Obuh, O.S. 'Drama as Instrument for Mass Mobilization: A Critical Analysis of some MAMSER Drama Programmes in Nigeria', In: Theatre and Politics in Nigeria. Malomo and Gbilekaa (ed.) Ibadan: Caltop Publishers Ltd.

[19]. Osofisan, F.,1986. 'Talks in 1986 in Muyiwa Awodiya', (ed.) Excursion in Drama and Literature. Ibadan: Kraft Books.

[20]. Vazquez, A.S.,1979. 'On Art and Society' In Art and Society. London: The Merlin Press.

[21]. Zelizer, C.,2003. The Role of Artistic Processes in peace building in Bosnia - Herzegovina', In: Peace and Conflict Studies (ed.) Honggang, Y.S. Associates, vol. 10, No. 2. 